\title{
FGF Signaling Mediates Regeneration of the Differentiating Cerebellum through Repatterning of the Anterior Hindbrain and Reinitiation of Neuronal Migration
}

\author{
Reinhard W. Köster ${ }^{1}$ and Scott E. Fraser ${ }^{2}$ \\ ${ }^{1}$ Gesellschaft für Strahlenforschung-National Research Center for Environment and Health, Institute of Developmental Genetics, 85764 Neuherberg- \\ Munich, Germany, and ${ }^{2}$ Biological Imaging Center, Beckman Institute (139-74), California Institute of Technology, Pasadena, California 91125
}

To address the regenerative capability of the differentiating hindbrain, we ablated the cerebellum in wild-type and transgenic zebrafish embryos. These larvae showed no obvious locomotive malfunction several days after the ablation. Expression analysis and in vivo time-lapse recording in GFP (green fluorescent protein)-transgenic embryos indicate that cerebellar neuronal cells can regenerate from the remaining anterior hindbrain. The onset of regeneration is accompanied by repatterning within the anterior hindbrain. Inhibition of FGF signaling immediately after cerebellar ablation results in the lack of regenerating cerebellar neuronal cells and the absence of cerebellar structures several days later. Moreover, impaired FGF signaling inhibits the repatterning of the anterior hindbrain and the reexpression of rhombic lip marker genes soon after cerebellar ablation. This demonstrates that the hindbrain is highly plastic in recapitulating early embryonic differentiation mechanisms during regeneration. Moreover, the regenerating system offers a means to uncouple cerebellar differentiation from complex morphogenetic tissue rearrangements.

Key words: zebrafish; cerebellum; regeneration; plasticity; neuronal migration; bioimaging

\section{Introduction}

Throughout vertebrates, the cerebellum functions in controlling body posture, maintaining balance, coordinating locomotion, and contributing to motor learning (Ide and Tompkins, 1977; Fiez, 1996; Gao et al., 1996; Altman and Bayer, 1997; Boyden et al., 2004; Morton and Bastian, 2004). The ease of analyzing such phenotypes combined with the stereotyped layered organization of the cerebellar cortex has made the cerebellum a favorite model tissue for analyzing neurogenesis, cell migration, and cell patterning in the brain (Miale and Sidman, 1961; Hatten and Heintz, 1995; Voogd and Glickstein, 1998).

Grafting studies show that the patterning of the cerebellum and hindbrain remain plastic, because the hindbrain develops during somitogenesis stages (Grapin-Botton et al., 1995; Itasaki et al., 1996; Kulesa et al., 2000; Schilling et al., 2001). The cerebellar primordium arises in the anterior hindbrain from the dorsal region of rhombomere 1 adjacent to and under the influence of

Received Jan. 10, 2006; revised May 29, 2006; accepted May 31, 2006.

This work was generously supported by the National Institutes of Health, the Caltech Biological Imaging Center, and the German Ministry for Education and Research through BioFuture Award 0311889. We thank Tanya Demyanenko and Aura Keeter for excellent technical assistance and animal care. We thank Nilima Prakash for critical discussion of this manuscript. We thank the members of the Fraser, Wurst, and Bally-Cuif laboratories for discussion and helpful suggestions. We are grateful to Shuo Lin for providing us with the transgenic gata1:gfp zebrafish line. For the generous gift of the zebrinll antibody, we thank Richard Hawkes. We thank Hazel Sive, Laure Bally-Cuif, Michael Brand, and Bernard Thisse for kindly providing zebrafish cDNA constructs.

Correspondence should be addressed to Reinhard Köster, Gesellschaft für Strahlenforschung-National Research Center for Environment and Health, Institute of Developmental Genetics, Ingolstädter Landstraße 1, 85764 Neuherberg-Munich, Germany. E-mail: Reinhard.Koester@gsf.de.

DOI:10.1523/JNEUROSCI.0095-06.2006

Copyright $\odot 2006$ Society for Neuroscience $\quad 0270-6474 / 06 / 267293-12 \$ 15.00 / 0$ the isthmic cells of the midbrain-hindbrain boundary (MHB) (Joyner, 1996; Wingate and Hatten, 1999; Wang and Zoghbi, 2001). When isthmic tissue is transplanted to different hindbrain regions, it can induce cerebellar development from the alar plate (Martinez et al., 1995), indicating that the MHB can impose cerebellar development onto even posterior rhombomeres.

Dissecting the molecular mechanisms of the MHB organizer has become an intense research field (Joyner, 1996; Rhinn and Brand, 2001; Wang and Zoghbi, 2001; Wurst and Bally-Cuif, 2001). A variety of results show that FGF signal transduction is an essential player. Mice and zebrafish mutants devoid of FGF8 function lack a cerebellum (Meyers et al., 1998; Reifers et al., 2000); ectopic FGF8 in the midbrain/hindbrain induces genes normally expressed in the cerebellum, and ectopic cerebellar development in the midbrain (Martinez et al., 1999; Irving and Mason, 2000; Sato et al., 2001). Rather than instructing cerebellar fate, recent studies suggest that FGF8 may act by restricting midbrain fate via maintaining the posterior expression boundary of Otx2 (Foucher et al., 2006).

Cerebellar patterning eventually results in cerebellar primordium rotation and long-distance neuronal migration (Miale and Sidman, 1961; Fujita, 1967; Köster and Fraser, 2001; Gilthorpe et al., 2002; Sgaier et al., 2005). Uncoupling neuronal differentiation from tissue rearrangements would mostly facilitate addressing the molecular mechanisms of cerebellar cell behavior. In research on hindbrain patterning, key interactions have been revealed by studying their recapitulation during the reformation of rhombomere boundaries after tissue grafting (Guthrie and Lumsden, 1991), as well as the regeneration of ablated MHB cells 
or individual rhombomeres (Diaz and Glover, 1996). The plasticity of the hindbrain revealed during somitogenesis stages promises that key events in cerebellar development may be recapitulated during regeneration at organogenesis stages during ongoing hindbrain differentiation.

Here, we combine intravital imaging in zebrafish embryos with genetics and in vivo manipulation to challenge cerebellar differentiation and hindbrain plasticity. Although neuronal migration is well underway at the stages studied, we find that the hindbrain still has an immense capability to regenerate the differentiating cerebellum. This regeneration requires FGF signaling to repattern and thereby recruit neuronal cells derived from the adjacent dorso-anterior hindbrain.

\section{Materials and Methods}

Maintenance of fish. Raising, spawning, and maintaining of zebrafish lines were performed as described previously (Kimmel et al., 1995; Westerfield, 1995).

Morphological stainings and expression analysis. To visualize the cellular organization of the brain, embryos were soaked overnight in $0.001 \%$ Bodipy Ceramide (Invitrogen, San Diego, CA) and rinsed shortly before image recording.

mRNA in situ hybridization and antibody stainings were performed as described previously (Köster et al., 1997). From embryos $72 \mathrm{~h}$ postfertilization (hpf) or older, the brains were dissected before the expression analysis procedure, and up to $1 \%$ Triton X-100 was added to all solutions for better probe or antibody penetration.

The monoclonal antibody anti-zebrinII (1:1000) (Lannoo et al., 1991) to identify cerebellar Purkinje neurons was detected with DAB using a peroxidase-coupled anti-mouse IgG monoclonal antibody (1:300; Jackson ImmunoResearch, West Grove, PA). Pictures of the obtained stainings were captured on a Zeiss Axioplan microscope using an Axiocam HRc camera (Zeiss, Oberkochen, Germany) and processed with Adobe Photoshop 6.0.

Intravital imaging. Still images of embryos or larvae stained with Bodipy Ceramide and embryos of the transgenic gatal:gfp 781 strain were recorded on an inverted LSM410 confocal microscope (Zeiss).

Noninvasive intravital time-lapse imaging was performed as described in detail (Köster and Fraser, 2004). Briefly, embryos were anesthetized in $0.01 \%$ tricaine in $30 \%$ Danieau medium containing $0.75 \mathrm{~mm}$ phenylthiourea (PTU) to prevent pigmentation. After embedding in 1.2\% ultra-low gelling agarose, embryos were cultured on an inverted LSM410 confocal microscope (Zeiss) at $29^{\circ} \mathrm{C}$. Three-dimensional stacks of pictures of the cerebellar anlage were recorded every $12-15 \mathrm{~min}$ at an interval of 3-5 $\mu \mathrm{m}$ over total depths between 30 and $60 \mu \mathrm{m}$ using a $40 \times$ Plan-Apochromat objective. Pictures of individual time points were projected in a maximum intensity projection into a single image per time point with these images subsequently being animated as a movie in QuickTime. The first and last frame of each movie was overlaid with a transmitted light image for better orientation. Note, quickly emerging and disappearing signals forming stripes are caused by green fluorescent protein (GFP)expressing fluorescent moving blood cells in gatal:gfp 781 strain embryos indicating the health of the imaged specimen.

Surgical ablation of the differentiating cerebellum. Embryos were anesthetized at $36 \mathrm{hpf}$ with $0.01 \%$ tricaine (MS22; 3-aminobenzonic acid ethylester) in 30\% Danieau/0.75 mM PTU followed by embedding in a drop of $1.2 \%$ ultra-low gelling agarose on their left side with the right side facing up. Microinjection needles were used for a triangular cut along the midbrain-hindbrain boundary and the ventral edge of rhombomere 1 to remove the entire cerebellum. Embryos were immediately fixed in $4 \%$ paraformaldehyde or allowed to recover in 30\% Danieau/0.75 mм PTU.

In the case in which transgenic gatal:gfp 781 strain embryos were used, successful ablation of the entire differentiating cerebellum was scored between 56 and $60 \mathrm{hpf}$ based on the complete absence of GFP-expressing cells in the dorso-anterior hindbrain. The presence of a few GFPfluorescent cells on the left side in a few embryos can be used as an internal control that GFP expression had been activated as in nonoper- ated transgenic specimens. Because this showed that the right cerebellar domain was entirely ablated with the highest confidence, likely because of the embedding procedure, images of expression patterns were always captured from the right hindbrain side for consistency reasons. Recorded images of the right hindbrain side were reflected horizontally (Fig. $2 F$ ) using Adobe Photoshop to display them in the common orientation with the embryonic head to the left. Only embryos with complete absence of GFP-expressing cells in the dorso-anterior hindbrain were used for intravital time-lapse imaging.

Inhibition of FGF signaling. To inhibit FGF signaling, embryos were incubated in the dark in 30\% Danieau/0.75 mM PTU/0.2\% DMSO containing the small molecule inhibitor 3-[3-(2-carboxyethyl)-4methylpyrrol-2-methylidenyl]-2-indolinone (SU5402) (Calbiochem, La Jolla, CA) at a concentration of $20 \mu \mathrm{M}$. Control embryos $(n=18)$ incubated in 30\% Danieau/0.75 mu PTU/0.2\% DMSO alone showed proper regeneration after cerebellar ablation.

\section{Results}

\section{Cerebellar differentiation is characterized by long-term neuronal migration}

Any analysis of the regenerative capacity of the zebrafish hindbrain requires a means to repeatedly identify specific cell types. A strain from the stable transgenic line gatal:GFP (denoted no. 781) (Long et al., 1997) is ideally suited to this purpose, because in the 781 strain, GFP is expressed not only in circulating blood cells but also ectopically in various neuronal populations throughout the CNS including upper rhombic lip (URL)-derived neuronal precursors of the cerebellum. Thus, this transgenic zebrafish line offers the possibility to reproducibly identify the same neuronal populations within the cerebellum over the course of cerebellar differentiation.

GFP fluorescence in the 781 strain first appears $\sim 48 \mathrm{hpf}$ in cells along the entire URL. These fluorescent neuronal precursors were followed by in vivo time-lapse confocal microscopy for up to $44 \mathrm{~h}$ ( $n=7$ time-lapse movies). The labeled cells migrate tangentially toward the MHB where they turn into a ventral direction to migrate ventrally along the MHB (Fig. $1 A-C$, blue arrowheads). Finally, these URL-derived cells settle in a cluster at the anteroventral base of rhombomere 1 (Fig. $1 \mathrm{~F}$, blue dashed circle) (supplemental movie 1, available at www.jneurosci.org as supplemental material). Migration occurs through leading and trailing process dynamics as described for earlier URL-derived neuronal precursors (Köster and Fraser, 2001). Thus, anteroventral migration from the upper rhombic lip proceeds from $\sim 24 \mathrm{hpf}$ for $\sim 3 \mathrm{~d}$ when migration diminishes and the expression of marker genes for differentiated cerebellar neurons such as granule cells and Purkinje cells expand.

\section{The zebrafish URL appears to be subdivided along its mediolateral axis}

The URL contributes to several neuronal populations (Wingate and Hatten, 1999; Lin et al., 2001; Machold and Fishell, 2005; Wang et al., 2005). The above intravital time-lapse imaging was complemented from the dorsal side ( $n=7$ time-lapse movies). These movies demonstrate that GFP-fluorescent cells over the entire length of the URL migrate tangentially in an anterior direction toward the $\mathrm{MHB}$ followed by a laterally oriented migration along the MHB (Fig. 1G-J, arrowheads). Two clusters of GFP-positive neurons arise close to the MHB, one at the lateral edge of the developing cerebellum (blue dashed circle) corresponding to forming neuronal clusters already observed in the lateral view movies. This neuronal cluster is fed by migratory cells originating from the lateral two-thirds of the URL. Cells originating from the remaining third of the URL close to the dorsal mid- 

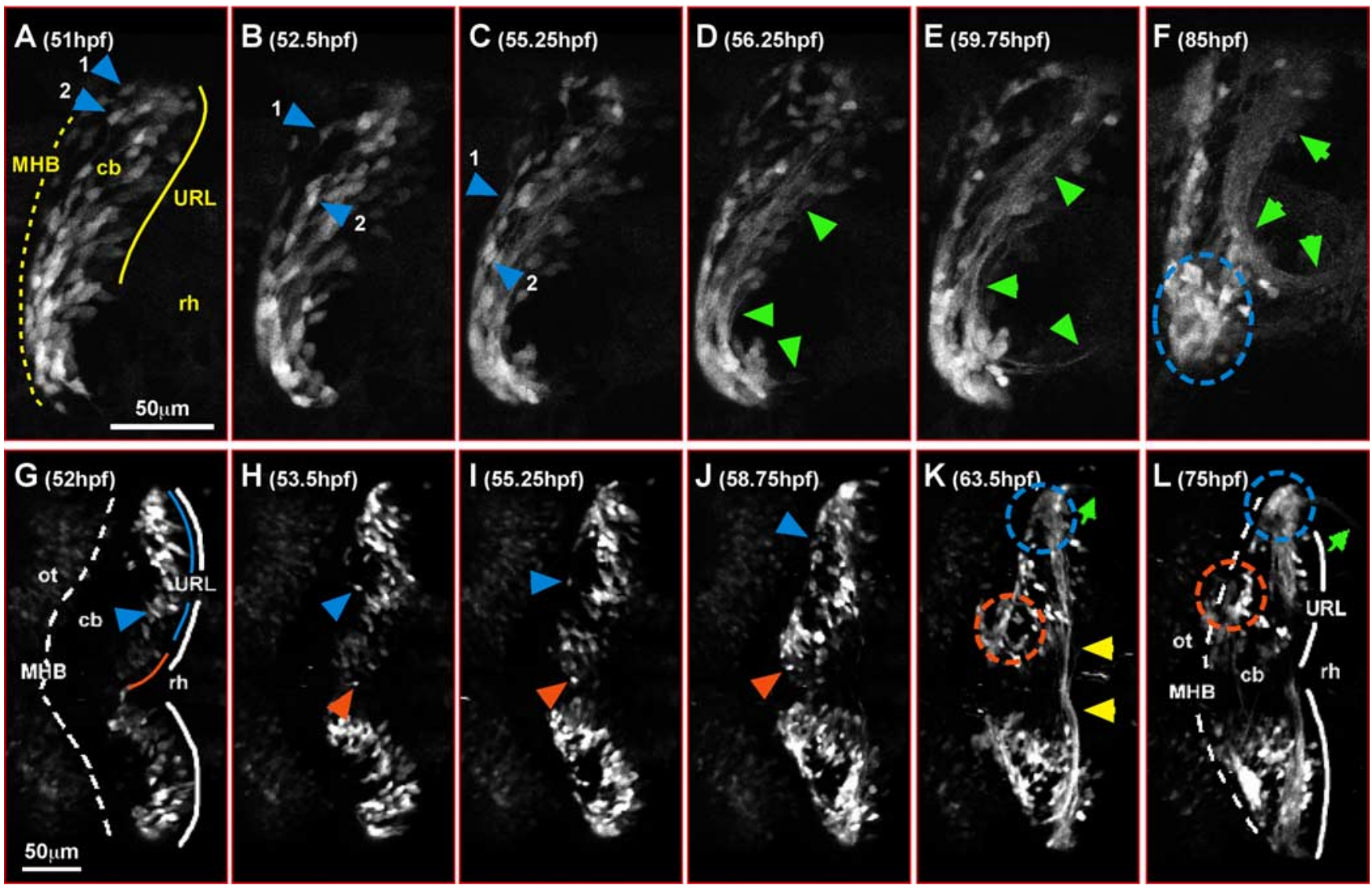

Figure 1. Neuronal migration from the upper rhombic lip in the transgenic gata1:GFP 781 strain. $\boldsymbol{A}-\boldsymbol{F}$, Lateral view of the developing cerebellum; pictures from individual time points of a time-lapse microscopy study of a transgenic 781 strain embryo are shown. For a schematic overview of the zebrafish cerebellum and migratory pathways, please refer to Figure 1 fin Köster and Fraser (2001). $A$-C, GFP-expressing neuronal precursors appear $\sim 48 \mathrm{hpf}$ in the URL from where they leave by migrating toward the MHB followed by a ventral migration along the MHB (blue arrowheads mark two individually traced cells) to settle in a cluster at the ventrolateral edge of rhombomere 1 ( $\boldsymbol{F}$, blue dashed circle). Around $60 \mathrm{hpf}$, the formation of an axon fascicle at the posterior border of the cerebellum can be observed ( $\boldsymbol{D}-\boldsymbol{F}$, green arrowheads) that projects ventrally and subsequently caudally into posterior rhombomeres (supplemental movie 1 , available at www.jneurosci.org as supplemental material). G-L, Dorsal view of the developing cerebellum, pictures from individual time points of a time-lapse microscopy study of a transgenic 781 strain embryo are shown. $\mathbf{G}-J$, GFP-expressing neuronal precursors leave the URL migrating anteriorly toward the MHB (blue and orange arrowheads). Whereas cells originating close to the dorsal midline settle in a cluster closer to the midline $(\boldsymbol{K}, \boldsymbol{L}$, orange dashed circle), cells originating further laterally migrate along the MHB to form the ventrolateral cluster of neurons $(\boldsymbol{K}, \boldsymbol{L}$, blue dashed circle) observed in the lateral time-lapse study $(\boldsymbol{F})$ (supplemental movie 2, available at www.jneurosci.org as supplemental material). $\boldsymbol{K}, \boldsymbol{L}$, The time-lapse analysis reveals that fascicle forming axons project toward the dorsal midline and cross the midline ( $\boldsymbol{K}$, yellow arrowheads) before projecting ventrally along the posterior border of the cerebellum and subsequently into the hindbrain (green arrow). cb, (erebellar anlage; ot, optic tectum; rh, rhombencephalon.

line contribute to a second cluster (orange dashed circle) positioned closer to the dorsal midline (supplemental movie 2, available at www.jneurosci.org as supplemental material).

\section{The differentiating zebrafish cerebellum regenerates} very efficiently

During somitogenesis stages, patterning of the hindbrain is still plastic (Grapin-Botton et al., 1995; Itasaki et al., 1996; Kulesa et al., 2000; Schilling et al., 2001). During organogenesis, at $36 \mathrm{hpf}$ the differentiation of the zebrafish cerebellum is well underway characterized by intense long-distance neuronal migration from the URL (Köster and Fraser, 2001). To address whether regeneration of differentiating cerebellar structures is still possible, we established a survival surgery protocol in which the entire cerebellar compartment is ablated along with the ventral part of rhombomere 1 (Fig. 2A,B). After ablation of the larval cerebellum, the wound heals quickly within $30 \mathrm{~min}$ leading to a fusion of the midbrain to the anterior rhombencephalon lacking the usually interspersed mediolateral cerebellar territory (Fig. 2C,D, black arrowhead). To ensure that the entire cerebellar domain and the URL have been removed, some specimens were fixed immediately after the ablation and analyzed for the expression of the rhombic lip marking gene atonall. In $36 \mathrm{hpf}$ wild-type embryos, atonall expression covers the URL, the entire dorsal extent of the cerebellum and lower rhombic lip derived cells in the anterior hindbrain (Fig. 2 E); in contrast, after the ablation, embryos of the same developmental stage completely lack the mediolateral atonal1-expressing cerebellar domain (Fig. $2 F ; n=15$ of 16; black arrowhead). This indicates that the entire cerebellum is removed reliably by our microsurgery.

At around d 6, zebrafish larvae swim upright, have control over balance and body posture, and show oriented swimming behavior, typical locomotive functions controlled by the cerebellum (Ide and Tompkins, 1977; Elbert et al., 1983). When the differentiating cerebellar cortex of rat embryos is irradiated or lesioned by microsurgery, the animals recover better and show fewer locomotive malfunctions the younger they are at treatment (Altman, 1976; Altman and Bayer, 1997; Molinari et al., 1990). We examined whether zebrafish embryos show locomotive defects several days after their differentiating cerebellum is ablated. When zebrafish embryos were allowed to recover for several days after cerebellar ablation, they showed control of body posture, 


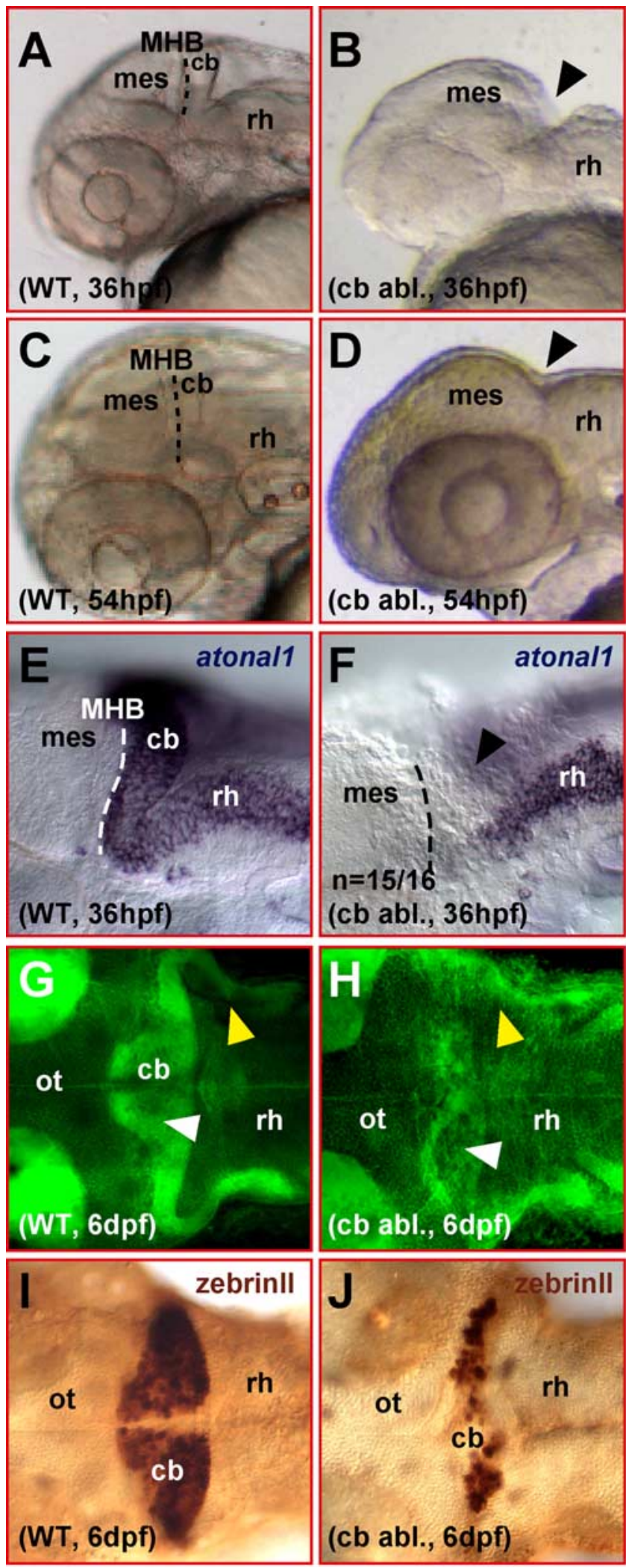

Figure 2. Ablated differentiating zebrafish cerebellum appears to regenerate. $\boldsymbol{A}-\boldsymbol{D}$, Lateral view of a zebrafish head showing that the mediolateral developing cerebellum posterior to the midbrain - hindbrain boundary $(\boldsymbol{A}$, WT) is fully ablated by survival surgery ( $\boldsymbol{B}$, arrowhead) at 36 hpf. This surgical ablation leads to the fusion of the midbrain to the anterior rhombencephalon lacking a cerebellar compartment at the MHB (compare $\boldsymbol{C}, \boldsymbol{D}$, arrowhead). $\boldsymbol{E}, \boldsymbol{F}$, Lateral views. Analysis of atonal 1 expression by mRNA in situ hybridization right after surgical ablation of the cerebellar tissue shows that no atonal1-expressing cerebellar cells are left behind posterior to the midbrain ( $\boldsymbol{F}$, arrowhead). $\boldsymbol{G}, \boldsymbol{H}$, Dorsal views. Bodipy Ceramide staining of cellular mem balance and locomotion similar to wild-type larvae at $6 \mathrm{~d}$ postfertilization ( $\mathrm{dpf}$ ), suggesting that cerebellar neuronal cells might have regenerated after the ablation procedure. We thus stained 6-d-old larvae with Bodipy Ceramide, a vital fluorescent label that stains cellular membranes and thus neuropil intensely. Confocal microscopy revealed that a cerebellar domain (Fig. 2G, $H$, white arrowhead) as well as the caudally projecting major axon fascicles (Fig. 2G,H, yellow arrowhead) found in transgenic 781 strain larvae were present in larvae that had undergone cerebellar ablation. Furthermore, anti-zebrinII immunohistochemistry at 6 $\mathrm{dpf}$ indicated the presence of differentiated Purkinje cells in larvae in which the entire cerebellar tissue had been removed at 36 hpf (Fig. $2 I, J$ ). This suggests that a well organized cerebellum can regenerate after removal of the differentiating cerebellum at 36 hpf.

To further substantiate our findings, we repeated the ablation of the cerebellum on homozygous transgenic 781 strain embryos. Approximately $20 \mathrm{~h}$ after the ablation, most embryos showed the complete absence of GFP-positive cells in the dorso-anterior hindbrain posterior to the $\mathrm{MHB}$, indicating that the entire cerebellum including the GFP-fluorescent cell-generating URL had been excised (Fig. 3, compare $A, B$ ). In a few embryos, some remaining GFP-fluorescent cells could be observed, but only on the left side of the anterior hindbrain. These cells might have been missed because of the embedding procedure making the left cerebellar one-half less accessible for the ablation procedure. This occasional presence of a few GFP-fluorescent neuronal cells on the left cerebellar side (Fig. 3C) $20 \mathrm{~h}$ after the ablation served as an internal control that GFP expression in the cerebellum had been activated at this developmental age. Because this showed that the right side of the cerebellum was entirely ablated with the highest confidence, only the right side of the dorso-anterior hindbrain was used for subsequent analysis. When the right hindbrain of these operated transgenic specimens was reexamined at $6 \mathrm{dpf}$, numerous GFP-expressing neurons were observed clustering ventrally along the new midbrain-hindbrain boundary (Fig. 3E) as in nonoperated transgenic larvae (Fig. 3D) or the left cerebellar side of the same embryo (Fig. $3 F$ ). Regeneration of GFPexpressing neurons occurred in $89 \%$ of cerebellar-ablated transgenic 781 strain larvae $(n=34$ of 38$)$. This demonstrates that differentiating cerebellar neurons, URL-derived cerebellar neurons, and Purkinje cells, are being regenerated in zebrafish very efficiently.

Rhombic lip marker genes become reexpressed in the dorsoanterior hindbrain after cerebellar ablation

To address whether genes expressed early in the rhombic lip become reexpressed during the regeneration process, 781 strain embryos were subjected to cerebellar ablation at $36 \mathrm{hpf}$ and fixed either immediately or at $72 \mathrm{hpf}$. In each of these specimens, successful ablation of the entire cerebellum was confirmed at $54 \mathrm{hpf}$ by determining that no GFP-expressing cells were present on the right or both sides of the dorso-anterior hindbrain. atonal1 and zicl (formerly termed $o p l$ ) are among the earliest genes identifying the rhombic lip and their derived cells (Wang and Zoghbi,

branes and neuropil reveals that larvae, which have undergone cerebellar excision $(\boldsymbol{H})$, have formed a cerebellar compartment (white arrowhead) and cerebellar axon tracts (yellow arrowhead) at $6 \mathrm{dpf}$. I, J, Dorsal views. Furthermore, zebrinll antibody stainings reveal the presence of likely regenerated Purkinje neurons after ablation of the cerebellum at $36 \mathrm{hpf}$. cb, Cerebellum; mes, mesencephalon; ot, optic tectum; rh, rhombencephalon; WT, wild type. 

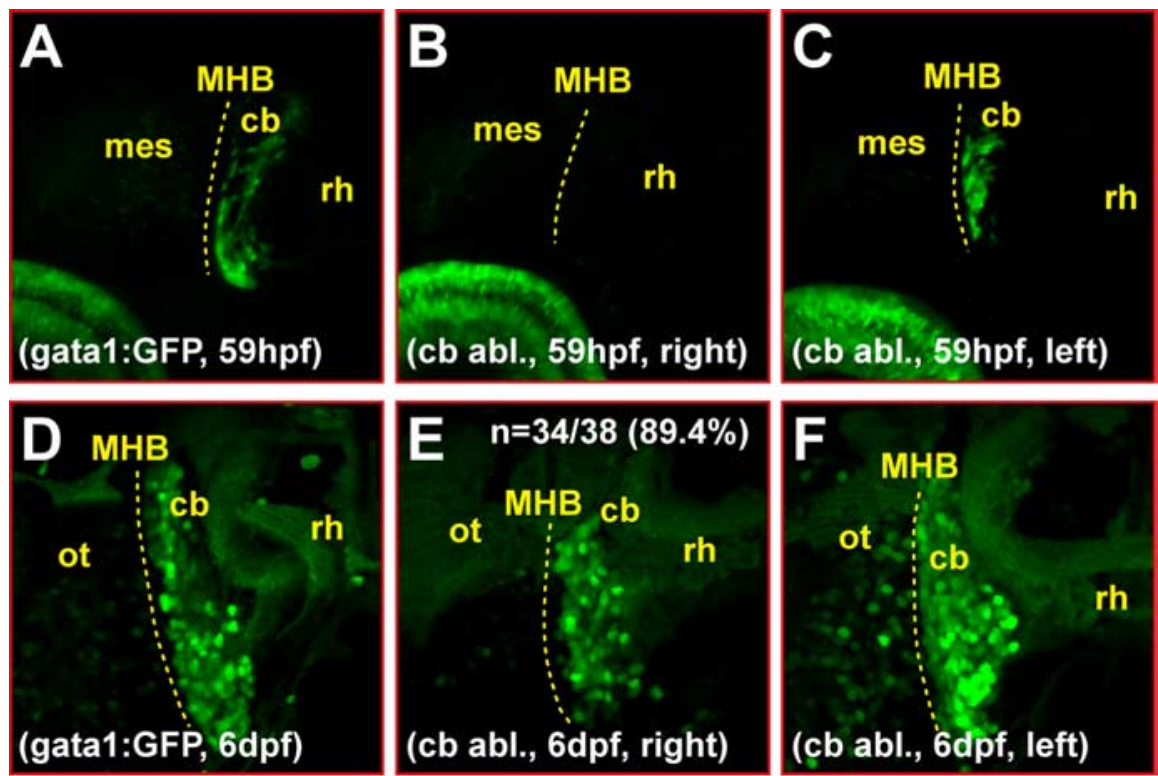

Figure 3. Neuronal regeneration of the zebrafish differentiating cerebellum is very efficient. $\boldsymbol{A}-\boldsymbol{F}$, Lateral views. Surgical excision of the differentiating cerebellum at $36 \mathrm{hpf}$ leads to the absence of GFP-fluorescent neuronal URL-derived cells in transgenic gata1:GFP 781 strain embryos at $59 \mathrm{hpf}(\boldsymbol{B})$, indicating that the cerebellum including the URL is removed completely. The presence of some GFP-fluorescent cells in the previous left cerebellar domain in a few embryos ( $\boldsymbol{C}$; same embryo as shown in $\boldsymbol{B}$ ) ensures that GFP expression in the cerebellum has been activated as in nonoperated transgenic embryos $(\boldsymbol{A})$ some time before the examination. In $89 \%(n=38)$ of transgenic embryos that were allowed to recover after surgical removal of the cerebellum at 36 hpf and lacking GFP-expressing neuronal cells at $59 \mathrm{hpf}$, numerous GFP-fluorescent neurons could be found along the MHB, forming clusters in the ventral cerebellar region at $6 \mathrm{dpf}(\boldsymbol{E})$ (note that pictures from the right cerebellar side displayed in $\boldsymbol{B}$ and $\boldsymbol{E}$ were taken from the same larvae) similar to the cerebellum in nonoperated transgenic counterparts $(\boldsymbol{D})$ or the left cerebellar side of the operated specimen $(\boldsymbol{F})$. cb, Cerebellum; mes, mesencephalon; ot, optic tectum; rh, rhombencephalon; WT, wild type.

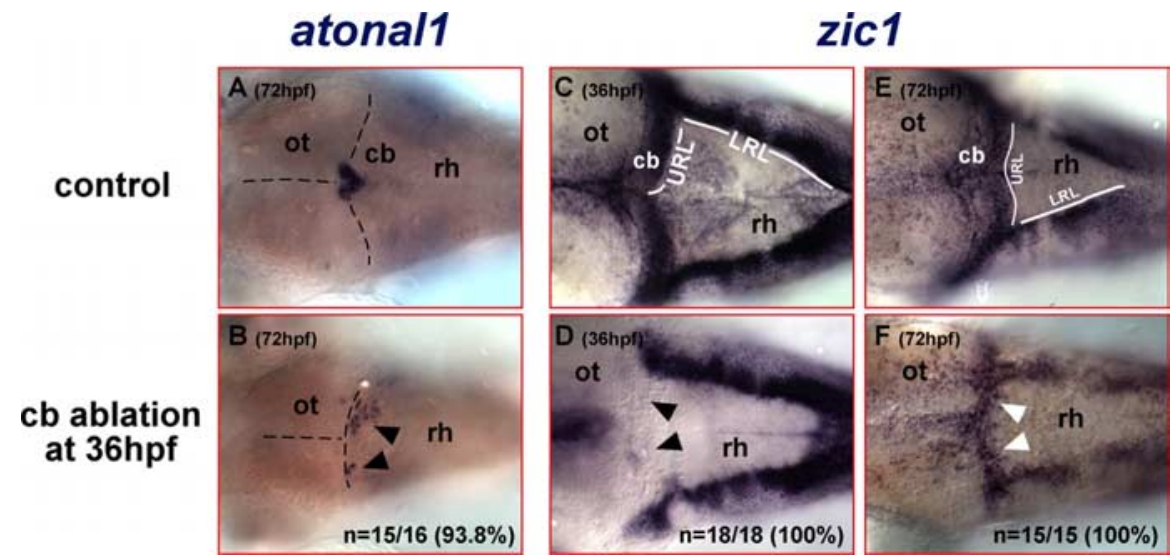

Figure 4. The anterior hindbrain reexpresses early rhombic lip marker genes after ablation of the differentiating cerebellum. $\boldsymbol{A}-\boldsymbol{F}$, Dorsal views of the anterior rhombencephalon of embryos that have been analyzed by mRNA in situ hybridization. $\boldsymbol{A}, \operatorname{In} 72$ hpf wild-type embryos, atonal 1 is expressed in the forming valvula cerebelli at the dorsal midline abutting the posterior optic tectum, whereas its expression in the lateral halves of the cerebellum has ceased (compare with Fig. $2 E$ ). $\boldsymbol{B}$, In contrast, excision of the cerebellum at $36 \mathrm{hpf}$ results in ectopic atonal1-expresssing cells in the lateral halves of the dorso-anterior rhombencephalon at $72 \mathrm{hpf}$. C, The zebrafish zic 1 homolog is expressed in the upper and lower rhombic lips and their derived cells at 36 hpf; thus zic1-expressing cells cover the entire dorsal aspect of the cerebellum. D, Excision of the differentiating cerebellum at $36 \mathrm{hpf}$ disrupts the continuous zic 1 expression domain between lower and upper rhombic lips, because no zic1-expressing cells in the dorso-anterior rhombencephalon posterior to the optic tectum can be detected, indicating that cerebellar ablation leaves no URL cells behind. Strikingly, a mediolateral zic1 expression domain reappears along the new MHB in the anterior rhombencephalon after recovery at $72 \mathrm{hpf}(\boldsymbol{F}$, white arrowheads) again connecting both lower rhombic lips as in wild-type embryos $(\boldsymbol{E})$. This reexpression of atonal1 and zic 1 suggests the reestablishment of rhombic lip fate in cells of the anterior hindbrain after cerebellar ablation. cb, Cerebellum; LRL, lower rhombic lip; ot, optic tectum; rh, rhombencephalon.

2001; Machold and Fishell, 2005; Wang et al., 2005). Ablation of the cerebellum leaves no atonall-expressing cells behind in the mediolateral expression domain of the cerebellar folds in the dorso-anterior hindbrain (Fig. 2 E, F). At $72 \mathrm{hpf}$, atonal1 expres- sion in wild-type embryos is absent from the cerebellar folds and demarcates only the forming valvula cerebelli at the dorsal midline protruding under the optic tectum (Fig. 4A). In contrast, embryos that underwent cerebellar ablation at $36 \mathrm{hpf}$ lack a valvula-like atonall expression domain. Instead, patches of atonal1expressing cells appear in ectopic locations in the dorso-anterior hindbrain probably identifying regenerating cerebellar cells with URL characteristics (Fig. $4 B$, arrowheads; $n=15$ of 16 ).

Zicl is expressed earlier and in broader domains than atonal1 in wild-type embryos (Grinblat et al., 1998; Rohr et al., 1999). In the hindbrain, zicl is expressed throughout the upper rhombic lip and its derivatives at $36 \mathrm{hpf}$ as well as along the lower rhombic lip, thus covering the entire dorsal aspect of the differentiating cerebellum and outlining the IVth ventricle (Fig. $4 C)$. Ablation of the cerebellar tissue leaves no zicl-expressing cells in the cerebellar region behind leading to the lack of this mediolateral zicl expression domain (Fig. $4 D$, arrowheads; $n=18$ of 18 ). However, when cerebellar-ablated embryos were allowed to recover, a mediolateral zicl expression domain along the new MHB spreads across the dorso-anterior hindbrain to connect again the lower rhombic lips at $72 \mathrm{hpf}$ (Fig. $4 F$, white arrowheads; $n=15$ of 15). This reappearing zicl expression is reminiscent of the mediolateral zicl expression domain in the anterior hindbrain of untreated specimens (Fig. $4 E$ ), although the borders of reappearing zicl expression appear to be less sharp. This ectopic expression of rhombic lip marker genes suggests that regeneration of cerebellar tissue occurs from cells of the dorso-anterior hindbrain.

\section{Regenerating cerebellar neurons are} derived from the anterior hindbrain To address the origin and behavior of regenerating cerebellar neuronal precursors, we performed in vivo time-lapse recordings on transgenic 781 strain embryos after cerebellar ablation starting at $54 \operatorname{hpf}(n=3$ time-lapse movies). Embryos were selected that entirely lacked GFP-expressing precursors on both sides of the hindbrain where the cerebellum is usually localized (Fig. 5B; only ventrally localized GFPexpressing neurons close to the ventral midline of anterior rhombomeres can be observed; white arrowhead). At this stage, nonoperated transgenic counterparts show GFP-expressing neuronal precursors within their URL. (Fig. 5A; white arrowhead demarcates ventral GFP-expressing neurons of anterior rhombomeres). At $62 \mathrm{hpf}, 12 \mathrm{~h}$ later than in 781 strain embryos, GFP 

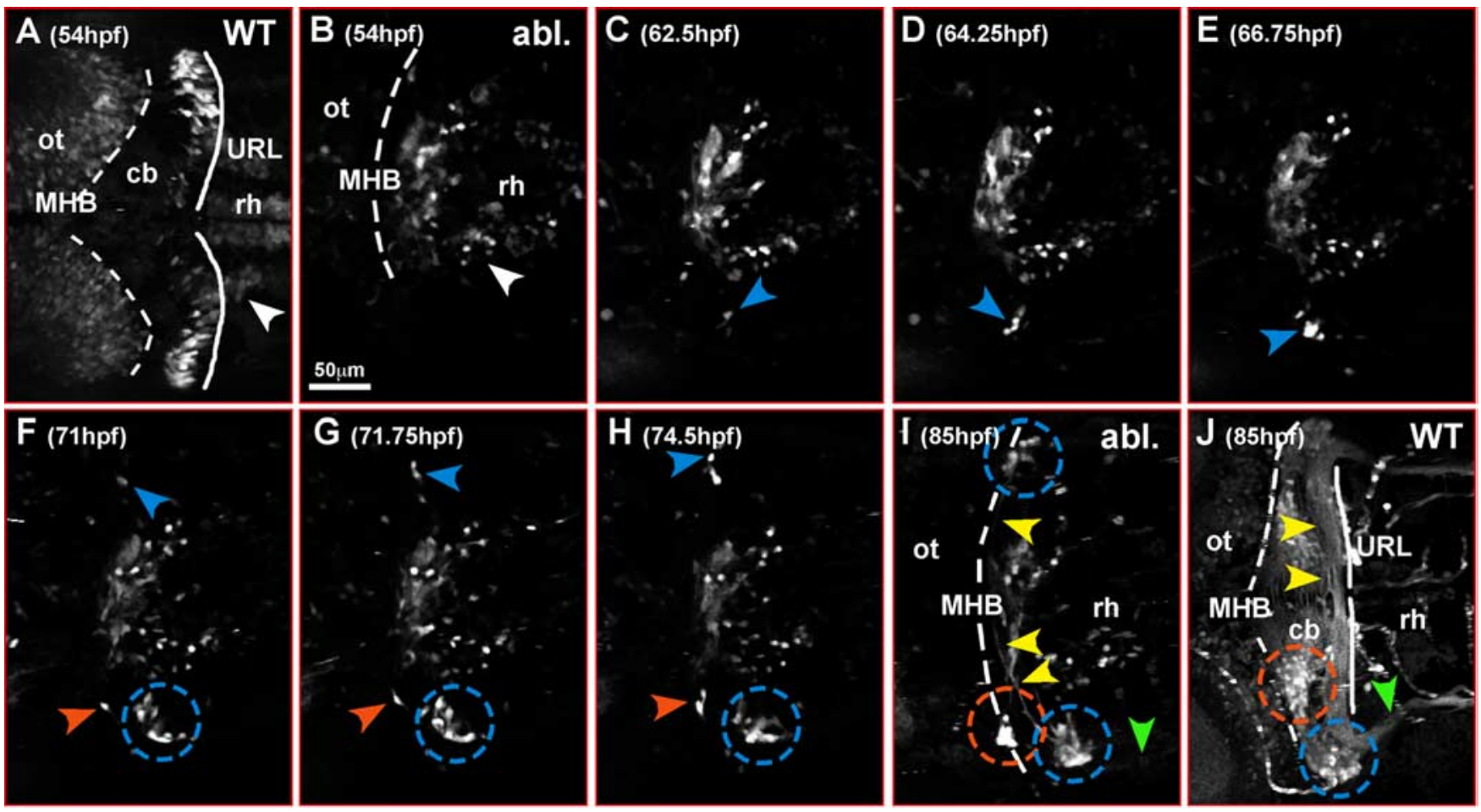

Figure 5. Regenerating neuronal cerebellar cells are derived from the lateral anterior rhombencephalon. $A-J$, Dorsal views of the anterior rhombencephalon of a time-lapse microscopy recording of a transgenic 781 strain embryo, in which cerebellar excision has been performed at $36 \mathrm{hpf}$. Only embryos with complete bilateral cerebellar ablation scored through the absence of GFP-expressing rhombic lip cells on both sides of the anterior hindbrain at $54 \mathrm{hpf}$ were used for time-lapse analysis. Pictures recorded at individual time points are being displayed to show the dynamics of the cerebellar neuronal regeneration processes (supplemental movie 3, available at www.jneurosci.org as supplemental material). $\boldsymbol{B}$, At 54 hpf, GFP-expressing URL-derived neuronal precursors are absent on both sides of the anterior hindbrain compared with wild-type embryos $(\boldsymbol{A})$, indicating that the differentiating cerebellum with the URL had been removed completely by surgical ablation. Only GFP-expressing neurons localized in the rhombencephalon posterior to the cerebellum can be detected in ventral positions (white arrowhead). C, Around 62 hpf, first GFP-expressing cells appear in ectopic locations on the far left side of the lateral dorso-anterior rhombencephalon (blue arrowhead); subsequently, GFP expression increases in these cells (D) and they migrate anteriorly toward the new MHB (E). Here they settle in a lateral position along the MHB forming a cluster of neurons ( $\boldsymbol{F}-\boldsymbol{H}$, blue dashed circle) and projecting commissural axons across the rhombencephalon ( $\boldsymbol{I}$, yellow arrowheads) reminiscent of the developmental course of URL-derived neuronal cells in nonoperated transgenic gata1:GFP 781 strain embryos ( $\boldsymbol{J}$ ) (compare with supplemental movie 2 , available at www.jneurosci.org as supplemental material). Starting $\sim 71 \mathrm{hpf}$, a similar regenerative event can be observed on the far right side of the anterior rhombencephalon $(\boldsymbol{F}-\boldsymbol{H}$, blue arrowhead; $\boldsymbol{I}$, blue dashed circle). In addition, a second cluster forms through migration of GFP-expressing neurons closer to the dorsal midline $(\boldsymbol{I}$, orange dashed circle) as in nonoperated transgenic gata1:GFP 781 strain embryos $(\boldsymbol{J})$; similarly, axons are being projected into posterior regions of the rhombencephalon (green arrowhead). Note that there is no contribution of regenerating cells to the contralateral cerebellar one-half. cb, Cerebellum; ot, optic tectum; rh, rhombencephalon.

fluorescence appears in cells in the dorsolateral anterior hindbrain of the cerebellar ablated embryos, first on the left side and $\sim 9$ h later (71 hpf) on the right side (Fig. 5C,F, blue arrowhead). After GFP fluorescence increases, the cells leave their place of origin and migrate anteriorly and along the new midbrain-hindbrain boundary, reminiscent of neuronal migration during normal cerebellar differentiation (Fig. $5 \mathrm{C}-\mathrm{H}$, blue and orange arrowheads). It is noteworthy that none of the regenerating cells was found to cross the dorsal midline contributing to structures of the contralateral side.

Similarly to nonmanipulated embryos (Fig. $5 J$ ), the regenerating neurons form clusters in lateral (blue dashed circle) and medial (orange dashed circle) positions along the new MHB (Fig. $5 I$ ), and in particular the neurons of the lateral cluster project axons across the dorsal midline (Fig. 5I, yellow arrowheads) and further posterior into the hindbrain (Fig. 5I, green arrowhead) (for dynamics of the regeneration process, see supplemental movie 3, available at www.jneurosci.org as supplemental material). The ectopic expression of rhombic lip marker genes in the dorsal anterior rhombencephalon together with our findings of the in vivo time-lapse analysis indicate that regeneration of neuronal structures of the zebrafish cerebellum after ablation at 36 hpf occurs by neuronal cells derived from the lateral region of the dorso-anterior hindbrain. These cells appear to acquire charac- teristics of URL-derived cells, recapitulating their migration, positioning and axon projection.

\section{Repatterning of the anterior rhombencephalon after cerebellar ablation}

To explain the origin of cerebellum regenerating cells, we analyzed potential changes in hindbrain patterning during cerebellar regeneration. At $36 \mathrm{hpf}$, the time point when the ablation of the cerebellum is performed, otx 2 is expressed in the mesencephalon with its posterior border demarcating the isthmus and thus the anterior border of the cerebellum (Fig. 6A). hoxa2 is expressed from rhombomere $2-5$ with its anterior border delineating the posterior border of the cerebellum (Fig. 6B) (Hunter and Prince, 2002). Thus, when both markers are being used simultaneously in mRNA in situ hybridization, their expression domains outline the cerebellum (Fig. 6C). The domain-specific expression of both marker genes is kept during zebrafish nervous system development until $72 \mathrm{hpf}$ (Fig. $6 E, F$ ), leaving only the cerebellum free of staining after mRNA in situ hybridization (Fig. 6G).

After ablation of the cerebellum, the expression domains of both marker genes are juxtaposed (Fig. $6 D$, dashed white circle; $n=20$ ), demonstrating again that the cerebellum is ablated completely by the microsurgical procedure. In contrast, when embryos were allowed to recover until $72 \mathrm{hpf}$ after cerebellar abla- 


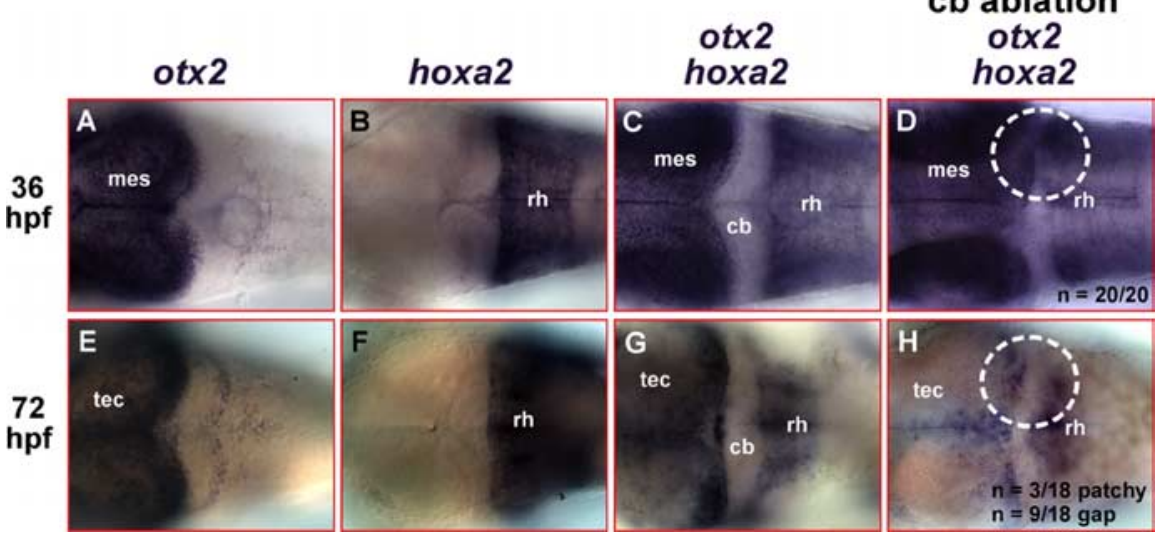

Figure 6. Repatterning of the anterior hindbrain accompanies the regeneration of the differentiating cerebellum. $\boldsymbol{A}-\boldsymbol{H}$, Dorsal views of the anterior hindbrain at $36 \mathrm{hpf}(\boldsymbol{A}-\boldsymbol{D})$ and $72 \mathrm{hpf}(\boldsymbol{E}-\boldsymbol{H})$, respectively, analyzed by mRNA in situ hybridization for the expression of the marker genes otx2, to demarcate the border of the posterior mesencephalon $(\boldsymbol{A}, \boldsymbol{E})$, and hoxa2, to demarcate rhombomere 2 through $5(\boldsymbol{B}, \boldsymbol{F})$, respectively. $\boldsymbol{C}, \mathbf{G}$, When the expression of both marker genes is detected simultaneously, only the differentiating cerebellum remains free of staining. Surgical ablation of the cerebellum at $36 \mathrm{hpf}$ thus results in the fusion of both expression domains $(\boldsymbol{D})$. When embryos were allowed to recover after the surgery until $72 \mathrm{hpf}$, hoxa2 is only expressed in patches or completely abolished in the anteriormost part of the hindbrain facing the new $\mathrm{MHB}(\boldsymbol{H})$. cb, Cerebellum; mes, mesencephalon; rh, rhombencephalon; tec, optic tectum.

tion at $36 \mathrm{hpf}$, either patches of cells free of the expression of both markers ( 3 of 18 larvae) or entire expression gaps ( 9 of 18 larvae) posterior to the MHB (Fig. $6 \mathrm{H}$ ) could be observed because of diminished hoxa2 staining in the anterior hindbrain. These less sharp borders of the hoxa 2 expression domain resemble the similar diffuse borders of reappearing zicl expression and patches of ectopic atonal 1 expression after cerebellar ablation (Fig. $4 B, F$ ), pointing at an ongoing change of pattering in the anterior hindbrain. These findings are consistent with an early regenerative mechanism that involves a repatterning of the anterior hindbrain leading to the suppression of hoxa2 expression posterior to the MHB to establish a new cerebellar territory.

\section{$f g f 8$ is still expressed in the differentiating brain}

FGF signaling, likely mediated by FGF8 emanating from cells of the $\mathrm{MHB}$, is a key player in cerebellar induction and maintenance, and could thus play an important role during the regeneration of the differentiating cerebellum. To first address whether $f g f 8$ is still expressed at the MHB during cerebellar differentiation, mRNA in situ hybridizations were performed. Similar to zebrafish embryos at tailbud and somitogenesis stages (Reifers et al., 1998), $f g f 8$ is still expressed in the isthmus at $36 \mathrm{hpf}$ demarcating the MHB (Fig. $7 A, B$ ). Surgical ablation of the differentiating cerebellum removes the posterior part of the $f g f 8$ expression domain in the isthmus but leaves the anterior isthmic part behind (Fig. 7C, $n=19$ of 20). Thus, FGF signaling, probably via FGF8, could represent a candidate to influence cerebellar regeneration because the excision of the cerebellum juxtaposes the anterior hindbrain with this FGF8 source at the newly created MHB. It is important, however, that this remaining $f g f 8$ expression domain in the center of the MHB is far removed from the dorsolateral hindbrain region from where regenerating cerebellar neurons have been observed to originate in our earlier time-lapse observations (Fig. $5 C, D, F, G$ ), making it fairly unlikely that $f g f 8$ expressing cells themselves regenerate the cerebellum. After ablation of the cerebellum, $f g f 8$ remains expressed but decreases over time until $72 \mathrm{hpf}$, as in wild-type embryos (data not shown).
Inhibition of FGF signaling can mimic the cerebellar phenotype of the zebrafish FGF8-mutant acerebellar

To address whether FGF signaling can be inhibited in vivo during cerebellar development, we made use of the small molecule inhibitor SU5402. This compound binds with high specificity to the ATPbinding site in the cytoplasmic region of FGF receptors, thereby blocking the phosphorylation of downstream targets of the FGF receptors (Mohammadi et al., 1997). To first establish FGF signaling-inhibiting conditions in zebrafish, we administered SU5402 before the induction of the cerebellum at the onset of gastrulation (50\% epiboly) at varying concentrations and scored the treated embryos at $30 \mathrm{hpf}$ for a phenocopy of FGF8-mutant acerebellar embryos, which lack a cerebellum (Reifers et al., 1998). At $20 \mu \mathrm{M}$ inhibitor concentration, treated embryos reliably failed to develop a cerebellum $(n=35$ of 35$)$ when scored for brain morphology, as cerebellar tissue could not be observed with Bodipy Ceramide stainings (Fig. 7, compare D, E, yellow star). Consistent with the absence of cerebellar tissue, inhibitor-treated specimens lacked expression of the FGF8dependent gene engrailed2, which is expressed across the MHB of wild-type embryos (Fig. $7 F, G$ ), and lacked the mediolateral atonall expression domain demarcating the cerebellar folds in wildtype counterparts (Fig. $7 H, I$ ).

\section{Inhibition of FGF signaling impairs regeneration of the differentiating cerebellum}

To analyze whether FGF signaling is involved in the regenerative processes observed after cerebellar ablation, the inhibitor SU5402 was applied to 781 strain transgenic embryos right after cerebellar ablation for a period of $24 \mathrm{~h}$. Cerebellar regeneration in these embryos was affected severely. In the vast majority of the embryos, no GFP-expressing neuronal precursors could be detected in the anterior hindbrain $\sim 72 \mathrm{hpf}$, resulting in $86 \%$ ( $n=24$ of 28 ) of the cerebellar-ablated and inhibitor-treated larvae lacking GFP-fluorescent cerebellar neurons at $7 \mathrm{dpf}$ (Fig. 8D). Control embryos treated with $0.2 \%$ DMSO alone showed proper regeneration ( $n=17$ of 18 ) (Fig. $8 C$ ). This indicates that FGF signaling after ablation of the differentiating cerebellum is required for the regeneration of cerebellar cells from the anterior hindbrain.

To exclude the possibility that inhibition of FGF signaling at 36 hpf simply prevents the induction of GFP-expressing rhombic lip-derived neuronal precursors, we treated 781 strain embryos at $36 \mathrm{hpf}$ for $24 \mathrm{~h}$ with SU5402 and analyzed the appearance of GFP-expressing neuronal precursors in the rhombic lip and their subsequent development. Despite impairment of FGF signaling, GFP-expressing neuronal precursors appeared in the rhombic lip at $\sim 48 \mathrm{hpf}$, similar as in untreated transgenic 781 embryos. These cells migrated along their characteristic pathway (Fig. 9A,B) and populated the cerebellum at $7 \mathrm{dpf}$ (Fig. $8 B ; n=28$ of 28 ) as in nontreated transgenic specimens (Fig. $8 A$ ). Thus, the GFPexpressing neuronal cells in the differentiating cerebellum of 781 strain embryos are neither induced nor controlled in their developmental time course by FGF signal transduction. This is consistent with recent findings that FGF signal transduction appears 
not to be required for the differentiation of the major cerebellar neuronal subtypes (Foucher et al., 2006). The absence of GFP-expressing neuronal precursors in the anteriormost hindbrain after cerebellar ablation can therefore still be used as a valid indication for a complete cerebellar ablation under conditions of impaired FGF signaling. Moreover, these results show that inhibition of FGF signal transduction specifically affects the regenerative properties of the anterior hindbrain at 36 hpf.

That the FGF signal responsible for successful cerebellar regeneration likely emanates from the remaining isthmic cells is suggested by two additional findings. When the posteriormost part of the mesencephalon was ablated along with the cerebellum at $36 \mathrm{hpf}$ the entire midbrain and anterior hindbrain decomposed by extensive cell death rather than regenerating the missing brain tissue. This is consistent with MHB-derived FGF8 maintaining differentiating midbrain and cerebellar tissue by securing cell survival as has been demonstrated by conditional mutagenesis in the mouse embryo (Chi et al., 2003). In addition, when cerebellar ablation was performed in 781 strain embryos at $60 \mathrm{hpf}$ regeneration of cerebellar tissue still occurred but to a lesser extent in only $42 \%$ of the embryos ( $n=8$ of 19) (data not shown) consistent with the decline of $f g f 8$ expression at the MHB during these later stages of organogenesis. These findings are also consistent with cerebellar irradiation and lesion studies performed on rats showing that the functional recovery is better the younger the developmental age of the rat during lesioning (Altman, 1976; Molinari et al., 1990; Altman and Bayer, 1997). Whether this age-dependent decrease in cerebellar regeneration in rats and zebrafish is indeed caused by the decrease in $f g f 8$ expression remains to be shown.

\section{Inhibition of FGF signaling abolishes repatterning of the hindbrain after cerebellar ablation}

The secreted signaling molecule FGF8 has been shown to be capable of repressing hoxa2 expression in the anterior hindbrain of chicken embryos (Irving and Mason, 2000; Mason et al., 2000) or in migrating neural crest cells (Trainor et al., 2002). To address whether FGF signaling is required for repatterning of the differentiating anterior hindbrain during regeneration, homozygous transgenic 781 embryos were subjected to surgical ablation of the cerebellum at $36 \mathrm{hpf}$ and subsequently treated with SU5402 for $24 \mathrm{~h}$. When analyzed for otx 2 and hoxa 2 expression at $72 \mathrm{hpf}$, these embryos showed fused expression domains of both genes at the new MHB (Fig. 9D). In contrast to cerebellar-ablated embryos in which FGF signaling was intact (Fig. $6 H$ ), a repression of hoxa2 expression could not be observed in the anterior hindbrain
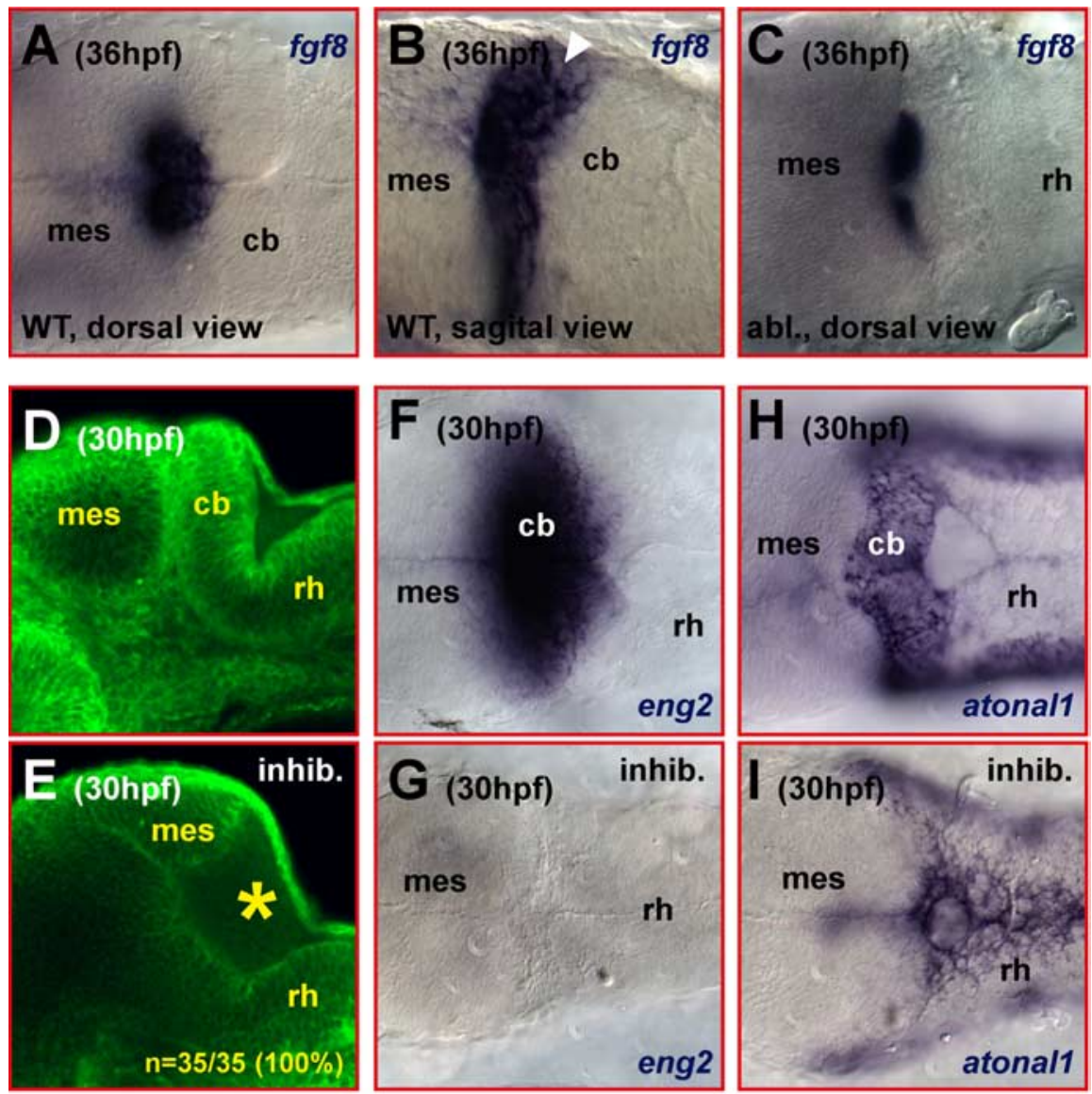

Figure 7. Partial expression of fgf8 remains in the isthmic region after ablation of the differentiating cerebellum. $\boldsymbol{A}-\boldsymbol{C}, \mathrm{mRNA}$ in situ hybridization detecting the expression of $f g f 8$. At $36 \mathrm{hpf}$, fgf8 is expressed in the isthmic region of the MHB $(\boldsymbol{A}$, dorsal view; $\boldsymbol{B}$, white arrowhead in sagittal section). Ablation of the cerebellum leaves the anterior part of the fgf8 expression domain behind type embryos $(\boldsymbol{F})$ and the loss of the mediolateral atonal 1 expression domain $(\boldsymbol{I})$ usually covering the entire dorsal extent of the developing cerebellum $(\boldsymbol{H})$. cb, Cerebellum; mes, mesencephalon; rh, rhombencephalon.

( $n=15$ of $17 ; 88 \%$ ), indicating that inhibition of FGF signaling impairs repatterning of the anterior hindbrain.

To exclude that FGF signaling is responsible for maintaining the restriction of the anterior border of hoxa2 expression to rhombomere 2 during this developmental period, homozygous 781 embryos were treated with SU5402 in parallel to the cerebellar ablated specimens. In these embryos, the cerebellum was still flanked anteriorly by otx 2 expression and posteriorly by hoxa 2 expression (Fig. 9C), demonstrating that lack of FGF signaling during cerebellar differentiation does not affect the spatial maintenance of hoxa2 expression consistent with findings during earlier stages of cerebellar development in zebrafish (Foucher et al., 2006).

To further support our finding that inhibition of FGF signaling abrogates repatterning of the anterior hindbrain after cerebellar ablation, we analyzed the expression of zic1. Within $36 \mathrm{~h}$ after cerebellar ablation, zicl had been found to become reexpressed in a mediolateral stripe in the anterior hindbrain along the MHB reminiscent to earlier embryonic stages of cerebellar 

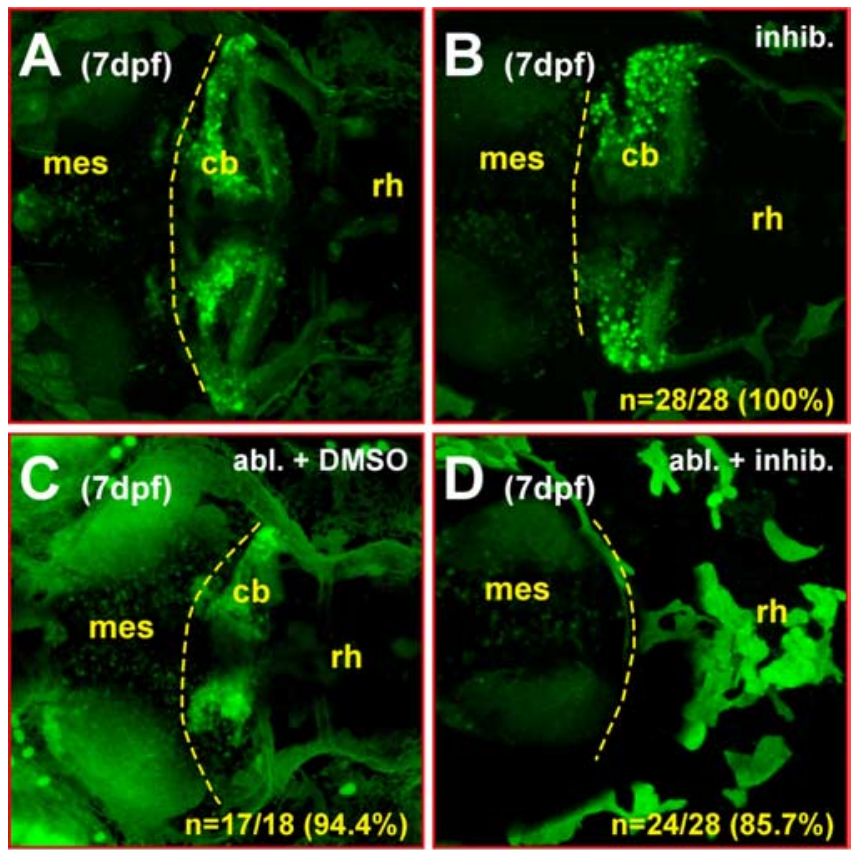

Figure 8. Inhibition of FGF signaling impairs the regeneration of ablated differentiating cerebellar tissue. $\boldsymbol{A}-\boldsymbol{D}$, Dorsal views. Brightest point projections of $100 \mu \mathrm{m} z$-stacks of pictures recorded at $3 \mu \mathrm{m}$ distance using laser-scanning confocal microscopy. A, At $7 \mathrm{dpf}$, the cerebellum of transgenic gata1:GFP 781 strain larvae is densely populated with GFP-expressing neurons forming posterior projecting axons. $\boldsymbol{B}$, SU5402-mediated inhibition of FGF signaling from 36 to $60 \mathrm{hpf}$ alone does not inhibit the formation of these cerebellar neurons. C, Likewise, regeneration is not affected in control embryos treated with $0.2 \%$ DMSO after ablation of the differentiating cerebellum. $\boldsymbol{D}$, In contrast, inhibition of FGF signaling severely impairs the regeneration of these cerebellar neurons from the anterior hindbrain after cerebellar ablation with almost no GFP-positive neurons present posterior to the MHB (yellow dashed line). cb, Cerebellum; mes, mesencephalon; rh, rhombencephalon.

development (Fig. 4E,F). When embryos were treated with SU5402 from 36 to $60 \mathrm{hpf}$, zic1 expression was unaffected compared with wild-type embryos at $72 \mathrm{hpf}$ (Fig. $4 E$ ), showing that the maintenance of zicl expression in the differentiating cerebellum is not dependent on FGF signaling ( $n=22$ of 22) (Fig. 9E). Inhibition of FGF signaling right after cerebellar ablation at 36 $\mathrm{hpf}$ for a period of $24 \mathrm{~h}$, however, affected the reexpression of $z i c 1$ severely. In these embryos, zicl expression appeared only in a few cells along the MHB in 58\% $(n=11$ of 19$)$ of the treated specimens and lacking in the remaining $42 \%$ ( $n=8$ of 19) (Fig. $9 F)$. This shows that FGF signaling, likely emanating from the remaining anterior part of the isthmus after cerebellar ablation, is required to repattern the anterior hindbrain to reestablish a zic1expressing cerebellar domain that is free of hoxa2 expression. Consistent with the finding that FGF signaling is required for cerebellar regeneration (Fig. $8 A-D$ ), these results suggest that repatterning of the anterior hindbrain is an early essential function of FGF signaling to allow cerebellar regeneration to occur.

\section{Discussion}

Analyzing the in vivo dynamics of cell behavior and their impact on morphogenesis is crucial to better understand the selforganization of the vertebrate embryo. Especially in the CNS, the complex interplay between signal transduction events and cellcell interactions needs to be elucidated by directly following and challenging cells to obtain insights into cell fate decisions and their rigidity.

Irradiation or lesion studies on rats have shown that the func- tional recovery of the cerebellum is better the earlier the lesion is performed during development (Altman, 1976; Molinari et al., 1990; Altman and Bayer, 1997). These data support our findings that zebrafish embryos can recover from cerebellar lesioning or ablation performed during embryogenesis and we extend this study by analyzing the underlying regenerative processes in vivo. An initial hindbrain reorganization step is followed by the recapitulation of the embryonic developmental program of zebrafish cerebellar differentiation. Regenerating neuronal cells recapitulate the characteristic migration from the rhombic lip to and along the midbrain-hindbrain boundary to form neuronal clusters at various positions along the $\mathrm{MHB}$ and begin to project axons into the hindbrain.

This suggests that, in addition to being positioned properly, regenerating cerebellar neuronal cells are also incorporated successfully into neuronal circuits of the hindbrain. The upright body posture and complex coordination of locomotion required for capturing prey and escaping, as observed in feeding larvae several days after cerebellar ablation, further supports our conclusion of a functional recovery of cerebellar neuronal circuits. These findings suggest that the hindbrain has an immense, longlasting plasticity that is not restricted locally to the ablation side close to the MHB only but extends to posterior rhombomeres that continue to provide guidance cues to steer cerebellar-derived axons to their target sites.

The plasticity of rhombomeric fates shortly after rhombomere formation during somitogenesis has been established in various studies in chicken and zebrafish embryos (Grapin-Botton et al., 1995; Itasaki et al., 1996; Kulesa et al., 2000; Schilling et al., 2001). We find that this plasticity must last over a long period in zebrafish, because our ablation followed by regeneration of differentiating cerebellar tissue occurs significantly later. The importance of the MHB organizer for the regeneration of differentiating cerebellar tissue became evident when we ablated the cerebellum together with the organizer. In such ablation experiments, no regeneration of cerebellar neuronal cells could be found. Instead, large parts of the midbrain decomposed by massive cell death. That cerebellar regeneration in these broader ablation experiments was not preceded nor accompanied by regeneration of the isthmus is in good agreement with findings in chicken embryos. There, only the juxtaposition of rhombomere 1 with midbrain tissue resulted in the regeneration of isthmic cells, whereas juxtaposition of rhombomere 2 and further posterior rhombomeres with midbrain tissue failed to do so (Irving and Mason, 1999). In addition, the observed degeneration resembles the phenotype caused by conditional inactivation of $f g f 8$ expression in mouse MHB cells during somitogenesis also leading to massive cell death in the midbrain and cerebellum (Chi et al., 2003) pointing at a critical function of FGF signaling in our cerebellar regeneration studies.

We have demonstrated that the anterior part of the isthmic $f g f 8$ expression domain remains after cerebellar ablation. Inhibition of FGF signal transduction after ablation of the differentiating cerebellum abrogates regeneration of cerebellar structures from the anterior hindbrain. Time-lapse analysis of the regeneration process showed that regenerating cerebellar cells are derived from the ipsilateral dorsolateral regions of the remaining anterior hindbrain and do not originate from or close by the more anterior small isthmic $f g f 8$ expression domain close to the dorsal midline (see supplemental movie 3, available at www. jneurosci.org as supplemental material). Thus, rather than giving rise to cerebellar regenerating cells themselves, isthmic FGFsecreting cells appear to induce cerebellar regeneration from the 
newly juxtaposed hindbrain tissue, thereby recruiting anterior hindbrain cells for a new, cerebellar fate.

This is supported by our gene expression studies after cerebellar ablation, which revealed that cerebellar regeneration is accompanied by repatterning of the anterior hindbrain through repression of hoxa2 and reinitiation of rhombic lip marker genes zicl and atonall. The importance of hoxa2 expression as an essential patterning signal in the developing anterior hindbrain has been defined by genetic experiments in higher vertebrates. Targeted inactivation of mouse hoxa 2 results in a caudal expansion of the cerebellum (Gavalas et al., 1997), whereas cerebellar granule cells exposed to ectopic hoxa2 expression adopt a fate similar to rhombomere 2-derived neurons (Eddinson et al., 2004). Furthermore, ectopic sources of FGF8 are capable of repressing hoxa2 expression in the chicken hindbrain during somitogenesis stages (Irving and Mason, 2000; Mason et al., 2000). Thus, repression of hoxa2 in the zebrafish anterior hindbrain after ablation of the differentiating cerebellum indicates that adjacent rhombomere cells adopt a more anterior fate, which is further supported by our findings that rhombic lip markers such as atonal1 and zicl become reexpressed in the ante-
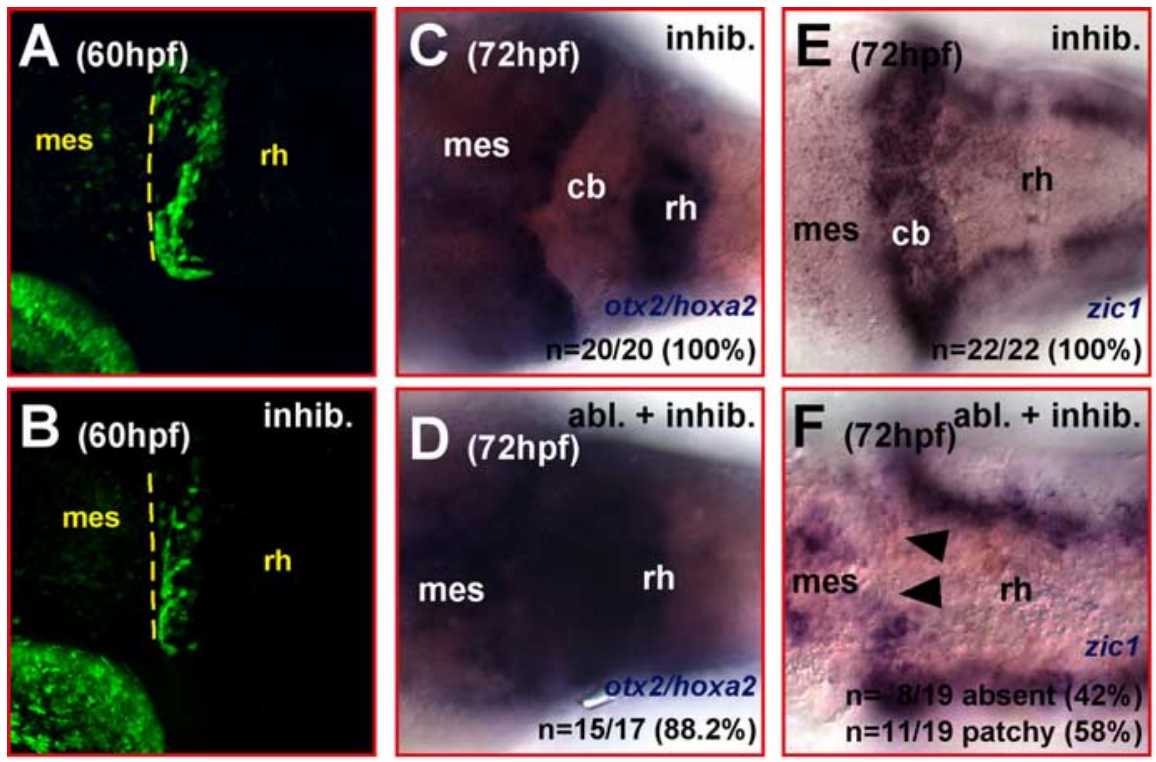

Figure 9. Inhibition of FGF signaling after cerebellar ablation impairs repatterning in the anterior hindbrain. $A, B$, Brightest point projection of z-stacks of 25 pictures from the cerebellum (lateral view) of gata1:GFP 781 strain embryos at $60 \mathrm{hpf}$ recorded at a distance of $3 \mu \mathrm{m}$ each by laser-scanning confocal microscopy. Inhibition of FGF signaling through administration of SU5402 from 36 to $60 \mathrm{hpf}$ does not affect the induction or migration of GFP-expressing cerebellar neuronal cells $(\boldsymbol{B})$, because they arise and migrate as in the cerebellum of untreated transgenic counterparts $(\boldsymbol{A}) . \boldsymbol{C}, \boldsymbol{D}$, Dorsal view of $72 \mathrm{hpf}$ gata1:GFP 781 strain embryo stained by mRNA in situ hybridization for the expression of otx 2 and hoxa2. Administration of SU 5402 from $36 \mathrm{hpf}$ until $60 \mathrm{hpf}$ does not affect the spatiotemporal maintenance of both expression domains ( $\boldsymbol{C}$; compare with Fig. $6 G)$. If the inhibitor treatment is preceded by surgical cerebellar ablation at $36 \mathrm{hpf}$, no repression of the hoxa2 expression close to the new MHB, as found after cerebellar ablation alone (compare with Fig. 6 H), can be observed $(\boldsymbol{D})$. SU5402 treatment from $36 \mathrm{hpf}$ until $60 \mathrm{hpf}$ does not affect zic1 expression at $72 \mathrm{hpf}$ ( $\boldsymbol{E}$; compare with Fig. 4E). However, when SU5402 is administered after cerebellar ablation, the reexpression of zic 1 in a mediolateral stripe along the new MHB indicative for cerebellar regeneration ( $\boldsymbol{F}$; compare with Fig. $4 F)$ is inhibited. cb, Cerebellum; mes, mesencephalon; rh, rhombencephalon.
The less sharp expression borders of these marker genes compared with nonoperated specimens just about the time when first regenerating GFP-expressing cells can be observed in the lateral anterior hindbrain of cerebellum-ablated 781 strain embryos likely reflect this ongoing repatterning. Moreover, we showed that inhibition of FGF signal transduction does not interfere with the induction or migration of GFP-expressing rhombic lipderived neuronal precursors in 781 strain embryos but leads to a failure in hoxa 2 repression and zic1 reexpression soon after cerebellar ablation. This argues for a hindbrain repatterning mechanism mediated by FGF signaling as an early essential step for successful regeneration of the differentiating cerebellum.

Currently, we cannot exclude the alternative that regeneration occurs from a small cell population in the dorsal anterior hindbrain that expresses zicl but is devoid of hoxa2 expression. Careful inspection of hoxa2 expression of successive developmental stages of zebrafish embryos until $72 \mathrm{hpf}$ shows that hoxa 2 appears to be expressed in a continuous domain in the anterior hindbrain with the dorsal rhombomere 1 as anterior expression border, making the regeneration of cerebellar neuronal cells from a zic1expressing but hoxa2-nonexpressing cell population in the anterior hindbrain unlikely. Unambiguous clarification of this possibility, however, has to await the production of specific antibodies or transgenic zebrafish lines expressing different fluorescent proteins to allow colocalization experiments to be performed for zebrafish Zic1 and Hoxa2.

In addition to FGF signaling, Wnt signal transduction could play an important role to further mediate the regeneration of the differentiating zebrafish cerebellum. Targeted mutagenesis in mice embryos has shown that the wnt1 gene is required for cere- bellar development (McMahon and Bradley, 1990; Thomas and Capecchi, 1990), but recent studies suggest that the main function of Wnt1 at the MHB is to regulate cell proliferation in the developing posterior midbrain (Panhuysen et al., 2004). We have observed that regeneration of differentiating cerebellar tissue is accompanied by a moderate, FGF-independent upregulation of cell proliferation in the anterior hindbrain. This moderate increase in cell proliferation could well be regulated by Wnt signal transduction. Compared with mouse, the function of Wnt signaling in zebrafish cerebellar development is less well understood. With the numerous Wnt ligands and their receptors being expressed in the zebrafish anterior hindbrain, their involvement in cerebellar regeneration is likely redundant as has been shown for the function of Wnt1, Wnt10b, and Wnt3a in maintaining the zebrafish isthmus (Lekven et al., 2003; Buckles et al., 2004). This makes an analysis of Wnt function in zebrafish cerebellar regeneration an interesting but challenging task.

The capacity of the hindbrain to replace cerebellar tissue even during differentiation stages is impressive. The cerebellum is one of the brain regions with the longest developmental program, because it is induced during gastrulation stages but becomes functional long after motility or vision is established. For example, in mammals, the postnatal differentiation of the cerebellum lasts several weeks (mouse) up to a year (humans). Thus, the cerebellum might be especially prone to environmentally induced malformations. The ability to replace cerebellar cells might help to overcome such insults.

Using our ablation strategy, the prolonged developmental process of cerebellar differentiation can be compressed to a defined time period uncoupling it from the extensive morphoge- 
netic rearrangements accompanying wild-type cerebellar development (Sgaier et al., 2005). Thus, enabling an analysis of cerebellar differentiation in a relatively simple and stable geometry should give access to elucidate individual cell behaviors such as fate acquisition, migration, cell positioning, and axon pathfinding. Such detailed intravital analysis should greatly facilitate to unravel how neuronal structures and circuits are being established in the vertebrate CNS.

\section{References}

Altman J (1976) Experimental reorganization of the cerebellar cortex. V. Effects of early X-irradiation schedules that allow or prevent the acquisition of basket cells. J Comp Neurol 165:31-48.

Altman J, Bayer SA (1997) Development of the cerebellar system in relation to its evolution, structure, and functions (Petralia P, ed). Boca Raton, FL: CRC.

Boyden ES, Katoh A, Raymond JL (2004) Cerebellum-dependent learning: the role of multiple plasticity mechanisms. Annu Rev Neurosci 27:581-609.

Buckles GR, Thorpe CJ, Ramel MC, Lekven AC (2004) Combinatorial Wnt control of zebrafish midbrain-hindbrain boundary formation. Mech Dev 121:437-447.

Chi CL, Martinez S, Wurst W, Martin GR (2003) The isthmic organizer signal FGF8 is required for cell survival in the prospective midbrain and cerebellum. Development 130:2633-2644.

Diaz C, Glover JC (1996) Appropriate pattern formation following regulative regeneration in the hindbrain neural tube. Development 122:3095-3105.

Eddinson M, Toole L, Bell E, Wingate RJT (2004) Segmental identity and cerebellar granule cell induction in rhombomere 1. BMC Biol 2:14-26.

Elbert OE, Ide CF, Duda M, Hunt RK (1983) Spastic mutant axolotl-identification of a phenocopy pathway with implications for the control of axolotl swimming by the vestibulocerebellum. J Comp Neurol 220:97-105.

Fiez JA (1996) Cerebellar contributions to cognition. Neuron 16:13-15.

Foucher I, Mione M, Simeone A, Acampora D, Bally-Cuif L, Houart C (2006) Differentiation of cerebellar cell identities in absence of Fgf signalling in zebrafish Otx morphants. Development 133:1891-1900.

Fujita S (1967) Quantitative analysis of cell proliferation and differentiation in the cortex of the postnatal mouse cerebellum. J Cell Biol 32:277-287.

Gao J-H, Parsons LM, Bower JM, Xiong J, Li J, Fox PT (1996) Cerebellum implicated in sensory acquisition and discrimination rather than motor control. Science 272:545-547.

Gavalas A, Davenne M, Lumsden A, Chambon P, Rijli FM (1997) Role of Hoxa-2 in axon pathfinding and rostral hindbrain patterning. Development 124:3693-3702.

Gilthorpe JD, Papantoniou EK, Chedotal A, Lumsden A, Wingate RJT (2002) The migration of cerebellar rhombic lip derivatives. Development 129:4719-4728.

Grapin-Botton A, Bonnin M-A, McNaughton LA, Krumlauf R, Le Dourain NM (1995) Plasticity of transposed rhombomeres: Hox gene induction is correlated with phenotypic modifications. Development 121:2707-2721.

Grinblat Y, Gamse J, Patel M, Sive H (1998) Determination of the zebrafish forebrain: induction and patterning. Development 125:4403-4416.

Guthrie S, Lumsden A (1991) Formation and regeneration of rhombomere boundaries in the developing chick hindbrain. Development 112:221-229.

Hatten ME, Heintz N (1995) Mechanisms of neural patterning and specification in the developing cerebellum. Annu Rev Neurosci 18:385-408.

Hunter MP, Prince VE (2002) Zebrafish hox paralogue group 2 genes function redundantly as selector genes to pattern the second pharyngeal arch. Dev Biol 247:367-389.

Ide CF, Tompkins RNM (1977) Neuroanatomy of Spastic, a behavior mutant of the mexican axolotl: Purkinje cell distribution in the adult cerebellum. J Comp Neurol 176:373-386.

Irving C, Mason I (1999) Regeneration of isthmic tissue is the result of a specific and direct interaction between rhombomere 1 and midbrain. Development 126:3981-3989.

Irving C, Mason I (2000) Signalling by FGF8 from the isthmus patterns anterior hindbrain and establishes the anterior limit of Hox gene expression. Development 127:177-186.

Itasaki N, Sharpe J, Morrison A, Krumlauf R (1996) Reprogramming Hox expression in the vertebrate hindbrain: influence of paraxial mesoderm and rhombomere transposition. Neuron 16:487-500.

Joyner AL (1996) Engrailed, Wnt and Pax genes regulate midbrain hindbrain development. Trends Genetics 12:15-20.

Kimmel CB, Ballard WW, Kimmel SR, Ullmann B, Schilling TF (1995) Stages of embryonic development of the zebrafish. Dev Dyn 203:235-310.

Köster R, Stick R, Loosli F, Wittbrodt J (1997) Medaka spalt acts as a target gene of hedgehog signaling. Development 124:3147-3156.

Köster RW, Fraser SE (2001) Direct imaging of in vivo neuronal migration in the developing cerebellum. Curr Biol 11:1858-1863.

Köster RW, Fraser SE (2004) Time-lapse microscopy of brain development. In: The zebrafish: cellular and developmental biology (Detrich III H, Zon LI, Westerfield M, eds), pp 205-233. San Diego: Academic.

Kulesa PM, Bronner-Fraser M, Fraser SE (2000) In ovo time-lapse analysis after dorsal neural tube ablation shows rerouting of chick hindbrain neural crest. Development 127:2843-2852.

Lannoo MJ, Ross L, Maler L, Hawkes R (1991) Development of the cerebellum and its extracerebellar Purkinje-cell projection in teleost fishes as determined by zebrin-II immunocytochemistry. Prog Neurobiol 37:329-363.

Lekven AC, Buckles GR, Kostakis N, Moon RT (2003) Wnt1 and Wnt10b function redundantly at the zebrafish midbrain-hindbrain boundary. Dev Biol 254:172-187.

Lin JC, Cai L, Cepko CL (2001) The external granule layer of the developing chick cerebellum generates granule cells and cells of the isthmus and rostral hindbrain. J Neurosci 21:159-168.

Long QM, Meng AM, Wang H, Jessen JR, Farrell MJ, Lin S (1997) GATA-1 expression pattern can be recapitulated in living transgenic zebrafish using GFP reporter gene. Development 124:4105-4111.

Machold R, Fishell G (2005) Math1 is expressed in temporally discrete pools of cerebellar rhombic-lip neural progenitors. Neuron 48:17-24.

Martinez S, Marin F, Nieto MA, Puelles L (1995) Induction of ectopic engrailed expression and fate change in avian rhombomeres: intersegmental boundaries as barriers. Mech Dev 51:289-303.

Martinez S, Crossley PH, Cobos I, Rubenstein JLR, Martin GR (1999) FGF8 induces formation of an ectopic isthmic organizer and isthmocerebellar development via a repressive effect on Otx2 expression. Development 126:1189-1200.

Mason I, Chambers D, Shamim H, Walshe J, Irving C (2000) Regulation and function of FGF8 in patterning of midbrain and anterior hindbrain. Biochem Cell Biol 78:577-584.

McMahon AP, Bradley A (1990) The Wnt-1 (Int-1) protooncogene is required for development of a large region of the mouse-brain. Cell 62:1073-1085.

Meyers EN, Lewandowski M, Martin GR (1998) An Fgf8 mutant allelic series generated by Cre- and Flp-mediated recombination. Nat Genet $18: 136-141$.

Miale IL, Sidman RL (1961) An autoradiographic analysis of histogenesis in the mouse cerebellum. Exp Neurol 4:277-296.

Mohammadi M, McMahon G, Sun L, Tang C, Hirth P, Yeh BK, Hubbard SR, Schlessinger J (1997) Structures of the tyrosine kinase domain of fibroblast growth factor receptor in complex with inhibitors. Science 276:955-960.

Molinari M, Petrosini L, Gremoli T (1990) Hemicerebellectomy and motor behaviour in rats. II. Effects of cerebellar lesion performed at different developmental stages. Exp Brain Res 82:483-492.

Morton SE, Bastian AJ (2004) Cerebellar control of balance and locomotion. Neuroscientist 10:247-259.

Panhuysen M, Vogt-Weisenhorn DM, Blanquet V, Brodski C, Heinzmann U, Beisker W, Wurst W (2004) Effects of Wntl signaling on proliferation in the developing mid-/hindbrain region. Mol Cell Neurosci 26:101-111.

Reifers F, Böhli H, Walsh EC, Crossley PH, Stainier DYR, Brand M (1998) Fgf8 is mutated in zebrafish acerebellar mutants and is required for maintenance of midbrain-hindbrain boundary development and somitogenesis. Development 125:2381-2395.

Reifers F, Walsh EC, Leger S, Stainier DYR, Brand M (2000) Induction and differentiation of the zebrafish heart requires fibroblast growth factor 8 (fgf8/acerebellar). Development 127:225-235. 
Rhinn M, Brand M (2001) The midbrain-hindbrain boundary organizer. Curr Opin Neurobiol 11:34-42.

Rohr KB, Schulte-Merker S, Tautz D (1999) Zebrafish zicl expression in brain and somites is affected by BMP and hedgehog signalling. Mech Dev 85:147-159.

Sato T, Araki I, Nakamura H (2001) Inductive signal and tissue responsiveness defining the tectum and the cerebellum. Development 128:2461-2469.

Schilling TF, Prince VE, Ingham PW (2001) Plasticity in zebrafish hox expression in the hindbrain cranial neural crest. Dev Biol 231:201-216.

Sgaier SK, Millet S, Villanueva MP, Berenshteyn F, Song C, Joyner AL (2005) Morphogenetic and cellular movements that shape the mouse cerebellum: insights from genetic fate mapping. Neuron 45:27-40.

Thomas KR, Capecchi MR (1990) Targeted disruption of the murine int-1 protooncogene resulting in severe abnormalities in midbrain and cerebellar development. Nature 346:847-850.
Trainor PA, Ariza-McNaughton L, Krumlauf R (2002) Role of the isthmus and FGFs in resolving the paradox of neural crest plasticity and prepatterning. Science 295:1288-1291.

Voogd J, Glickstein M (1998) The anatomy of the cerebellum. Trends Neurosci 21:370-375.

Wang VY, Zoghbi HY (2001) Genetic regulation of cerebellar development. Nat Rev Neurosci 2:484-491.

Wang VY, Rose MF, Zoghbi HY (2005) Math1 expression redefines the rhombic lip derivatives and reveals novel lineages within the brainstem and cerebellum. Neuron 48:31-48.

Westerfield M (1995) The zebrafish book. Eugene, OR: University of Oregon.

Wingate RJT, Hatten ME (1999) The role of the rhombic lip in avian cerebellum development. Development 126:4395-4404.

Wurst W, Bally-Cuif L (2001) Neural plate patterning: upstream and downstream of the isthmmic organizer. Nat Rev Neurosci 2:99-108. 